\title{
Estimation of Optimum Moisture Content and Maximum Dry Unit Weight of Fine-Grained Soils using Numerical Methods
}

\author{
Armand Augustin FONDJO ${ }^{1, *}$, Elizabeth THERON ${ }^{1}$ and Richard P. RAY ${ }^{2}$ \\ ${ }^{I}$ Department of Civil Engineering, Central University of Technology, Bloemfontein 9301, South Africa \\ ${ }^{2}$ Department of Structural and Geotechnical Engineering in Széchenyi István Egyetem University, \\ Györ 9026, Hungary
}

('Corresponding author's e-mail: aafondjo@outlook.com)

Received: 17 February 2021, Revised: 28 April 2021, Accepted: 5 May 2021

\begin{abstract}
Soil compaction is one of the basic engineering techniques, which is carried out to guarantee the stability of soils dependent on specified strength. Nonetheless, in large-scale construction projects, the estimation of compaction features required tremendous effort and time that can be saved utilizing empirical relationships at the initial phases. It becomes critical to develop models to predict the compaction features, namely the maximum dry unit weight $\left(\gamma_{\mathrm{dmax}}\right)$ and optimum water content $\left(\mathrm{W}_{\mathrm{OP}}\right)$. This article attempts to develop models to predict the $\gamma_{\mathrm{dmax}}$ and $\mathrm{W}_{\mathrm{OP}}$ of fine-grained clay soils. Geotechnical tests such as grain size distribution, Atterberg limits, specific gravity, and proctor compaction tests are performed to assess soil samples' physical and hyro-mechanical characteristics. Multivariate analysis is conducted using MINITAB 18 software to develop the predictive models. The validation process of developed models includes the determination coefficient, probability value $(p$ value), comparison of the predicted values with experimental values, comparison of the models proposed in this study with other existing models found in the recent literature, and employing a different soil data set. The predicted values obtained from the models proposed in this research project are more accurate than other models developed recently. The proposed models estimate the compaction features of finegrained clay soils with acceptable precision.
\end{abstract}

Keywords: Fine-grained soils, Maximum dry unit weight, Optimum water content, Geotechnical properties, Multivariate analysis

\section{Introduction}

The principal purpose behind soil compaction is to generate a soil material which can fulfill 3 essential requirements. First, the decrease of the subsequent settlement of the soil mass under live loads. Second, the reduction in permeability will successively prevent the development of enormous water stresses inducing liquefaction issues, and containing water in the case of earth dams. Finally, the enhancement of the shear resistance of the soil material. Nonetheless, the determination of compaction features in research workshop is arduous. It requires significant effort and time. Therefore, it is necessary to predict the compaction features with the support of the relationship between the compaction features and soil index properties easy to measure. The primary objective of this research work is to design models to predict the compaction features of fine-grained clay soils as an alternative to the compaction test. Researchers over the years attempted to develop models to predict the $\mathrm{W}_{\mathrm{OP}}$ and $\gamma_{\mathrm{dmax}}$. Sridharan and Nagaraj [1] investigated the effect of Atterberg limits on compaction features of fine-grained soils. The results revealed that the plastic limit (PL) bears a good relationship with the $\mathrm{W}_{\mathrm{OP}}$ and $\gamma_{\mathrm{dmax}}$ than the liquid limit (LL) and the plasticity index (PI). Therefore, the PL is suitable to design mathematical statements to estimate the compaction features. The proposed predictive equations are as follows: 
http://wjst.wu.ac.th

$W_{O P}=0.92 \times P L$

$\gamma_{\text {dmax }}=0.23 \times(93.3-P L)$

Mohd and Che [2] assessed the relationship between the Atterberg limits and the compaction features, and reported a similar interrelation between the Atterberg limits and the compaction features as given in Eqs. (3) - (4) below. However, the determination coefficient values of the predictive equations are smaller than 0.80 . Then, the models display a low strength correlation.

$W_{O P}=0.079 \times L L+0.24 \times P L+3.577 ; R^{2}=0.458$

$\gamma_{d \max }=-0.003 \times L L+0.007 \times P L+2.137 ; R^{2}=0.496$

Faizah [3] conducted a research work and reported a linear relationship between the Atterberg limits (PL, LL, PI) and $\mathrm{W}_{\mathrm{OP}}, \gamma_{\mathrm{dmax}}$ described in Eqs. (5) - (6), respectively for $\mathrm{W}_{\mathrm{OP}}$ and $\gamma_{\mathrm{dmax}}$. Nonetheless, the predictive equation exhibits a low strength correlation because the determination coefficients are smaller than 0.80 .

$$
\begin{aligned}
& W_{O P}=4.065-0.125 \times L L+0.180 \times P L ; R^{2}=0.517 \\
& \gamma_{d \max }=2.132-0.004 \times L L-0.006 \times P L ; R^{2}=0.588
\end{aligned}
$$

Sivrikaya et al. [4] investigated the correlation between the fine-grained soil compaction features to their PL based on 130 soil specimens. They reported that PL exhibits a significant impact on $\mathrm{W}_{\mathrm{OP}}$ and $\gamma_{\mathrm{dmax}}$ than the LL and PI. These results are in line with the investigation conducted by [1] and proposed similar predictive models. Eqs. (7) - (8) described the respective models to predict the $\mathrm{W}_{\mathrm{OP}}$ and $\gamma_{\mathrm{dmax}}$.

$W_{O P}=0.94 \times P L$

$\gamma_{\text {dmax }}=0.22 \times(96.32-P L)$

Noor et al. [5] reported that the Atterberg limits and the specific gravity influences the $\mathrm{W}_{\mathrm{OP}}$ and $\gamma_{\mathrm{dmax}}$. They developed a model to predict the $\mathrm{W}_{\mathrm{OP}}$ and $\gamma_{\mathrm{dmax}}$ of soil material utilizing Atterberg limits (PL, PI) and specific gravity. The proposed predictive Eqs. (9) - (10) for $\mathrm{W}_{\mathrm{OP}}$ and $\gamma_{\mathrm{dmax}}$ are as follows:

$$
\begin{aligned}
& W_{O P}=0.55 \times P L-0.36 \times P I-\left(\frac{G_{s}}{2.7}\right) \\
& \gamma_{\text {dmax }}=27-P L^{0.6}-P I^{0.33}-\left(\frac{G_{s}}{2.7}\right)
\end{aligned}
$$

Sing and Noor [6] developed predictive models to estimate $\mathrm{W}_{\mathrm{OP}}$ and $\gamma_{\mathrm{dmax}}$. The input variables are the Atterberg limits (PL, LL) and the specific gravity (Gs). Mathematical models to predict the $\mathrm{W}_{\mathrm{OP}}$ and the $\gamma_{\mathrm{dmax}}$ are given by: 


$$
\begin{aligned}
& W_{O P}=\left(\frac{P I}{G_{s}}\right)+3.4241823+(0.4624983 \times P L)-G_{s} \\
& \gamma_{d \max }=(-0.0890392) \times L L+19.046925+\frac{(S q r t(P L)+33.974626)}{(P L-(-1.3710165))}
\end{aligned}
$$

Naderi et al. [7] developed 2 mathematical models to predict the $\mathrm{W}_{\mathrm{OP}}$ and $\gamma_{\mathrm{dmax}}$ utilizing the genetic programming technique. The process relies on a pattern identification method that models the non-linear behaviour of complex design issues. The output variables are $\mathrm{W}_{\mathrm{OP}}$ and $\gamma_{\mathrm{dmax}}$. The input variables are the Atterberg limits, soil classification parameters, and specific gravity $\left(\mathrm{G}_{\mathrm{s}}\right)$. Eqs. (13) - (14) describes 2 numerical models to predict the $\mathrm{W}_{\mathrm{OP}}$ and $\gamma_{\mathrm{dmax}}$. The fine-grained content is $(\mathrm{F})$, sand content is $(\mathrm{S})$, gravel content (G). Moreover, the independent variables are not only the Atterberg limits like previous models. Besides, the addition of soil classification parameters and Gs as predictors enhances the efficiency of the models. Eqs. (13) - (14) describes 2 numerical models to predict the $\mathrm{W}_{\mathrm{OP}}$ and $\gamma_{\mathrm{dmax}}$.

$$
\begin{aligned}
& W_{O P}=0.1605 \times F+0.0811 \times S+0.0908 \times G-3.2203 \times G_{S}+0.2597 \times L L+0.1159 \times P L \\
& \gamma_{d \max }=0.1286 \times F+0.1707 \times S+0.1571 \times G+2.4415 \times G_{s}-0.0669 \times L L-0.0596 \times P L
\end{aligned}
$$

Đoković et al. [8] established the correlation between the LL, PL and compaction features using correlation-regression analysis and proposed models to predict the $\mathrm{W}_{\mathrm{OP}}$ and $\gamma_{\mathrm{dmax}}$ of clayey soils. Also, the determination coefficient of the models is equal to 0.73 . Thus, the models exhibit a moderate strength correlation.

$$
\begin{aligned}
& W_{O P}=4.18+0.16 \times L L+0.323 \times P L ; R^{2}=0.73 \\
& \gamma_{\text {dmax }}=2.14-0.007 \times L L-0.005 \times P L ; R^{2}=0.73
\end{aligned}
$$

Idris et al. [9] attempted to determine the $\mathrm{W}_{\mathrm{OP}}$ and $\gamma_{\mathrm{dmax}}$ from Atterberg limits (PI, LL, PL) and clay content $(\mathrm{F})$. The design of these numerical models to determine the compaction features is related to the statistical technique. These models exhibit a high strength correlation with the determination coefficients are higher than 0.80 . The models are described by Eqs. (17) - (18) given as follows:

$$
\begin{aligned}
& W_{O P}=-92.092 \times L L+92.521 \times P L+92.189 \times P I+0.179 \times F-4.74 ; \quad R^{2}=0.86 \\
& \gamma_{d \max }=-2.035 \times L L+2.034 \times P L+2.033 \times P I-0.004 \times F+2.142 ; \quad R^{2}=0.96
\end{aligned}
$$

Kok Shien et al. [10] developed simple correlation Eqs. to estimate the $\mathrm{W}_{\mathrm{OP}}$ and $\gamma_{\mathrm{dmax}}$ using a relatively simple index properties test. Three mathematical predictive models to determine the $\mathrm{W}_{\mathrm{OP}}$ and $\gamma_{\mathrm{dmax}}$ are designed based on multi-regression analyses. Models (19), (20), (21) estimate the $\mathrm{W}_{\mathrm{OP}}$ whereas models (22), (23), (24) determine the $\gamma_{\mathrm{dmax}}$. These models exhibit a high strength correlation because the determination coefficients are higher than 0.80 .

$$
\begin{aligned}
& W_{O P}=-0.2929 \times G-0.1174 \times S-0.1551 \times F+0.7378 \times L L ; \quad R^{2}=0.998 \\
& W_{O P}=-0.2646 \times G-0.2612 \times S-0.2452 \times F+2.6111 \times P I ; \quad R^{2}=0.997
\end{aligned}
$$


http://wjst.wu.ac.th

$$
\begin{aligned}
& W_{O P}=+2.4480 \times P I-8.8502 \times G ; R^{2}=0.996 \\
& \gamma_{d \max }=0.0285 \times G+0.0273 \times S+0.0270 \times F-0.0666 \times P I ; \quad R^{2}=1 \\
& \gamma_{d \max }=0.0219 \times G+0.02347 \times S+0.02457 \times F-0.01854 \times L L ; R^{2}=1 \\
& \gamma_{d \max }=-0.0475 \times P I+0.9443 \times G ; R^{2}=1
\end{aligned}
$$

Jyothirmayi et al. [11] investigated the fine-grained soils like red clay, black cotton soil, china clay, marine clay, silty clay collected across Telangana, and Andhra Pradesh in India. The results revealed that PL bears a good correlation with $\mathrm{W}_{\mathrm{OP}}$. Eq. (25) is developed using linear regression analysis.

$$
W_{O P}=12.00 \times e^{0.0181 \times P L} ; R^{2}=0.84
$$

Arif Hasnat et al. [12] attempted to determine the $\mathrm{W}_{\mathrm{OP}}$ and $\gamma_{\mathrm{dmax}}$ of soils utilizing the soil index properties. The statistical investigations determined the relationship of the Atterberg limits with $\mathrm{W}_{\mathrm{OP}}$ and $\gamma_{\mathrm{dmax}}$. The proposed predictive equations are as follows:

$$
\begin{aligned}
& W_{O P}=0.34 \times L L+0.17 \times P L+6.30 \\
& \gamma_{\text {dmax }}=21.07-0.119 \times L L-0.02 \times P L
\end{aligned}
$$

Firomsa and Quezon [13] conducted an experimental investigation to obtain a good relationship between the $\left(\mathrm{W}_{\mathrm{OP}}, \gamma_{\mathrm{dmax}}\right)$ and Atterberg limits of fine-grained soils. The $\mathrm{W}_{\mathrm{OP}}$ and $\gamma_{\mathrm{dmax}}$ bear a good relationship with PL and LL as a result of multiple linear regression analyses. Conclusively, both the LL and PL should be used to predict the $\mathrm{W}_{\mathrm{OP}}$ and $\gamma_{\mathrm{dmax}}$ of soil material. The predictive Eqs. (28) - (29) are given by:

$$
\begin{gathered}
W_{O P}=9.743+0.226 \times L L+0.114 \times P L ; \quad R^{2}=0.891 \\
\gamma_{d \max }=1.788-0.003 \times L L-0.004 \times P L ; \quad R^{2}=0.749
\end{gathered}
$$

More recently, Hussain and Atalar [14] attempted to develop a predictive equation between the LL and compaction features. Multiple linear regression analyses are performed on experimental data to design predictive models in terms of liquid limit (LL). The expression of the models is given by:

$$
\begin{aligned}
& W_{O P}=0.1809 \times L L+8.5179 \\
& \gamma_{\text {dmax }}=26.811-0.5198 \times W_{O P}(\%)
\end{aligned}
$$

In general, few models to predict the $\mathrm{W}_{\mathrm{OP}}, \gamma_{\mathrm{dmax}}$ are designed utilizing fine-grained clay soil material. The design of the reviewed equations uses different soil parameters as independent variables and various number of soil parameters. The number of independent variables and the type of soil material and are not always the same from one equation to another. Atterberg limits are the independent variables commonly used in the proposed models. The use of PI, PL in some reviewed equations is not efficient, PI and PL are dependent variables because of PI $=$ LL - PL. It is better to use LL (higher range of values, no 
http://wjst.wu.ac.th

need to evaluate plastic limit PL) than PI. Besides, Naderi et al. [7] and Kok Shien et al. [10] utilized the grain size distribution parameters and the Atterberg limits in their models. Noor et al. [5]; Singh and Noor [6] proposed models using the specific gravity and Atterberg limits. Moreover, Fondjo and Theron [15] proposed a mathematical concept utilizing differential function $(\partial)$ and the graphical technique to determine the $\mathrm{W}_{\mathrm{OP}}$ and $\gamma_{\mathrm{dmax}}$ of partially saturated fine-grained clay soils. The results revealed that the $\Delta \mathrm{W}_{\mathrm{OP}}$ and $\Delta \gamma_{\mathrm{dmax}}$ values are smaller than $0.5 \%$ and marginal in saturated soil mechanics. However, the total suction and matric suction values induced by $\Delta \mathrm{W}_{\mathrm{OP}}$ are significant for unsaturated soils. The mathematical approach gives an accurate assessment of the compaction features of partially saturated fine-grained clay soils. Conclusively, an extended investigation of the impact of soil properties on the $\mathrm{W}_{\mathrm{OP}}$ and $\gamma_{\mathrm{dmax}}$ of fine-grained clay soil is essential to develop and efficient predictive models for compaction features.

\section{Materials and testing program}

\section{Material}

The type of soil plays an essential role in the compaction features values. In this current study, soil samples are taken on-site by digging $50 \mathrm{~cm}$ from the soil surface. Fine-grained clay soil samples are selected to achieve different gradations and consistency limit values to encompass a wide range of compaction features.

\section{Testing program}

The evaluation of the soil samples' physical and hydro-mechanical properties is carried out according to the protocols and standards found in the literature. Sieve analysis [16]; hydrometer analysis [17]; Atterberg limits [18]; compaction test [19]; specific gravity [20].

\section{Multivariate analysis}

The multivariate analysis depicts a multi-factor data investigation. The multivariate technique defines models that connect the dependent variable and predictors. MINITAB 18 software is used to perform the multivariate analysis. The $\gamma_{\mathrm{dmax}}$ and $\mathrm{W}_{\mathrm{OP}}$ are the dependent variables. The predictor variables include Atterberg limits, particle size distribution, density and gradation measurements. The multivariate analysis is conducted for various models, including logarithmic, quadratic, linear, cubic, power, exponential, growth. The linear model displays a high strength correlation. Johnson [21] reported that the predictive multi-linear model takes the form of Eq. (32). The dependent variable is (T), the intercept is $\left(\xi_{\mathrm{o}}\right)$, the regression coefficient is $\left(\xi_{\mathrm{i}}\right)$, the number of relevant soil parameters is $(\mathrm{n})$, the predictor variable is $\left(\mathrm{Z}_{\mathrm{i}}\right)$, and the random error is $(\varepsilon)$.

$$
T=+\zeta_{o}+\sum_{i=1}^{n}\left(\zeta_{i} Z_{i}+\varepsilon\right)
$$

\section{Results and discussions}

\section{Material properties}

The material properties of soil samples are summarized in Tables $\mathbf{1}$ and 2. Particle size distribution estimations reveal that a given soil can mostly be granular, sandy, silty or clayey. This data is of extraordinary assistance in attempting to anticipate the mechanical properties of soils. PES, BFS, WIS, WES are fine-grained clay soils, more than $50 \%$ passing the No $200(0.075 \mathrm{~mm})$. Besides, for BES soil, $49.50 \%$ passing sieve No $200(0.075 \mathrm{~mm})$. Nonetheless, BES contained more fine-grained clay soils than sand and gravel. Moreover, the liquid limit values of PES-B, PES-C, BFS, WIS and WES are greater than $50 \%$ above the A-line of the plasticity chart. Thus, these soils exhibit high plasticity and classified $(\mathrm{CH})$. However, the liquid limit values of PES-A and BES are $<50 \%$. PES-A and BES soils portray low plasticity (CL). Besides, WES displays the smaller $\gamma_{\text {dmax }}$ values ranging from 15.65 to $16.29 \mathrm{kN} . \mathrm{m}^{-3}$. BES exhibits higher $\gamma_{\mathrm{dmax}}$ values ranging from 18.76 to $19.60 \mathrm{kN} . \mathrm{m}^{-3}$. Moreover, WIS, BFS, PES exhibits the $\gamma_{\mathrm{dmax}}$ mean values ranging respectively from 16.45 to $16.85,16.95$ to $17.58,17.99$ to $18.50 \mathrm{kN} . \mathrm{m}^{-3}$. On the 
http://wjst.wu.ac.th

other hand, WES displays higher $\mathrm{W}_{\mathrm{OP}}$ values ranging from 26.14 to $27.75 \%$. BES exhibits smaller $\mathrm{W}_{\mathrm{OP}}$ values ranging from 17.23 to $18.24 \%$. Moreover, PES, BFS, WIS exhibit the mean $\mathrm{W}_{\mathrm{OP}}$ values ranging respectively from 18.20 to $20.38,20.07$ to $23.00,24.03$ to $26.05 \%$. These results are justified by the fact that when the fine-grained clay soils content increases, the $\gamma_{\mathrm{dmax}}$ reduces, and the $\mathrm{W}_{\mathrm{OP}}$ increases simultaneously.

Table 1 Particle size distribution analysis results.

\begin{tabular}{|c|c|c|c|c|c|c|c|c|}
\hline \multirow[b]{2}{*}{$\begin{array}{c}\text { Soil } \\
\text { Designation }\end{array}$} & \multicolumn{3}{|c|}{ Gradation (\%) } & \multicolumn{5}{|c|}{ Measures of gradation } \\
\hline & $\begin{array}{c}\text { Fines } \\
\text { Clay } \\
+ \\
\text { Silt }\end{array}$ & Sand & Gravel & $\mathbf{D}_{10}$ & $\mathbf{D}_{30}$ & $D_{60}$ & $\begin{array}{l}\text { Coefficient of } \\
\text { curvature } \\
\left(\mathbf{C}_{\mathbf{c}}\right)\end{array}$ & $\begin{array}{l}\text { Coefficient of } \\
\text { uniformity } \\
\left(C_{u}\right)\end{array}$ \\
\hline PES-A & 52.19 & 30.75 & 16.03 & 0.00050 & 0.00900 & 0.16600 & 0.9759 & 332.000 \\
\hline PES-B & 54.51 & 32.45 & 12.16 & 0.00044 & 0.00450 & 0.12500 & 0.3724 & 287.356 \\
\hline PES-C & 58.45 & 31.97 & 9.45 & 0.00035 & 0.00200 & 0.08000 & 0.1426 & 228.571 \\
\hline BFS-A & 59.51 & 29.39 & 10.09 & 0.00050 & 0.00200 & 0.08000 & 0.1000 & 160.000 \\
\hline BFS-B & 61.83 & 29.49 & 8.38 & 0.00040 & 0.00150 & 0.06000 & 0.0938 & 150.000 \\
\hline BFS-C & 65.18 & 30.48 & 4.32 & 0.00036 & 0.00125 & 0.04500 & 0.0965 & 125.000 \\
\hline WIS-A & 67.52 & 26.80 & 4.85 & 0.00034 & 0.00133 & 0.03600 & 0.1445 & 105.882 \\
\hline WIS-B & 70.10 & 27.20 & 2.45 & 0.00027 & 0.0009 & 0.04500 & 0.0667 & 166.667 \\
\hline WIS-C & 74.78 & 23.98 & 1.21 & 0.00023 & 0.00070 & 0.02600 & 0.0819 & 113.043 \\
\hline WES-A & 73.00 & 23.50 & 2.56 & 0.00033 & 0.00090 & 0.0300 & 0.0818 & 90.900 \\
\hline WES-B & 78.11 & 18.71 & 1.98 & 0.00030 & 0.00060 & 0.0130 & 0.0923 & 43.333 \\
\hline WES-C & 82.98 & 15.92 & 1.10 & 0.00027 & 0.00043 & 0.0040 & 0.1712 & 13.333 \\
\hline BES-A & 49.50 & 44.00 & 6.48 & 0.0006 & 0.0080 & 0.1400 & 0.7619 & 233.333 \\
\hline BES-B & 49.58 & 42.83 & 7.48 & 0.0008 & 0.01750 & 0.2300 & 1.6640 & 287.500 \\
\hline BES-C & 49.66 & 40.45 & 9.64 & 0.00133 & 0.0300 & 0.3000 & 2.2550 & 225.563 \\
\hline
\end{tabular}

Table 2 Consistency limits and compaction features values.

\begin{tabular}{|c|c|c|c|c|c|c|c|}
\hline $\begin{array}{c}\text { Soil } \\
\text { Designation }\end{array}$ & $\begin{array}{c}\text { Liquid } \\
\text { Limit } \\
(\%)\end{array}$ & $\begin{array}{c}\text { Plastic } \\
\text { Limit } \\
(\%)\end{array}$ & $\begin{array}{c}\text { Plasticity } \\
\text { Index } \\
(\%)\end{array}$ & $\begin{array}{c}\text { Maximum } \\
\text { dry unit } \\
\text { weight } \\
\left(\mathrm{kN} \cdot \mathrm{m}^{-3}\right)\end{array}$ & $\begin{array}{l}\text { Optimum } \\
\text { water } \\
\text { content } \\
(\%)\end{array}$ & $\begin{array}{c}\text { Specific } \\
\text { gravity } \\
\text { (Gs) }\end{array}$ & $\begin{array}{l}\text { Unified Soil } \\
\text { Classification } \\
\text { System } \\
\text { (USCS) }\end{array}$ \\
\hline PES-A & 48.91 & 17.83 & 31.08 & 18.50 & 18.20 & 2.60 & $\mathrm{CL}$ \\
\hline PES-B & 51.08 & 18.62 & 32.46 & 18.21 & 19.01 & 2.63 & $\mathrm{CH}$ \\
\hline PES-C & 54.78 & 19.97 & 34.81 & 17.99 & 20.38 & 2.66 & $\mathrm{CH}$ \\
\hline BFS-A & 58.98 & 22.16 & 36.82 & 17.58 & 20.07 & 2.64 & $\mathrm{CH}$ \\
\hline BFS-B & 61.27 & 23.02 & 38.25 & 17.16 & 22.61 & 2.68 & $\mathrm{CH}$ \\
\hline BFS-C & 64.60 & 24.27 & 40.33 & 16.95 & 23.00 & 2.71 & $\mathrm{CH}$ \\
\hline WIS-A & 63.78 & 21.30 & 42.48 & 16.85 & 24.03 & 2.73 & $\mathrm{CH}$ \\
\hline WIS-B & 66.22 & 22.12 & 44.10 & 16.71 & 24.58 & 2.76 & $\mathrm{CH}$ \\
\hline WIS-C & 70.64 & 23.60 & 47.04 & 16.45 & 26.05 & 2.78 & $\mathrm{CH}$ \\
\hline WES-A & 69.45 & 19.58 & 49.87 & 16.29 & 26.14 & 2.73 & $\mathrm{CH}$ \\
\hline WES-B & 74.31 & 20.95 & 53.36 & 16.05 & 26.52 & 2.78 & $\mathrm{CH}$ \\
\hline WES-C & 78.94 & 22.26 & 56.68 & 15.65 & 27.75 & 2.83 & $\mathrm{CH}$ \\
\hline BES-A & 40.29 & 21.06 & 19.23 & 19.60 & 17.23 & 2.55 & $\mathrm{CL}$ \\
\hline BES-B & 43.59 & 22.79 & 20.80 & 19.20 & 18.13 & 2.59 & CL \\
\hline BES-C & 48.37 & 25.28 & 23.09 & 18.76 & 18.24 & 2.63 & $\mathrm{CL}$ \\
\hline
\end{tabular}




\section{limits \\ Analysis of the correlations between the compaction features $\left(W_{O P}, \gamma_{d m a x}\right)$ and the Atterberg}

Figure 1 describes the interaction between the $\gamma_{\mathrm{dmax}}$, liquid limit and plasticity index. Also, different colour patterns represent the distribution of the $\gamma_{\mathrm{dmax}}$ values on the surface plot. The blue represents the smaller values. The green, yellow, orange represent the mean values and the red represents the higher values. Further, the $\gamma_{\mathrm{dmax}}$ value decreases when the LL increases. The relationship is an exponential function given in Eq. (33) with a determination coefficient $R^{2}=98.25 \%$. Further, $\gamma_{\text {dmax }}$ values decrease when the PI increases. The relationship is an exponential function given in Eq. (34) with $\mathrm{R}^{2}=97.69 \%$. These results are explained through the increment of the Atterberg limits when the clay content increases. Then, the values of $\gamma_{\mathrm{dmax}}$ will decrease upon an increment of clay content. These results are in line with the outcomes of the investigations conducted by $[2,3,7-9,12-14]$ which revealed that the $\gamma_{\text {dmax }}$ decreases when the LL increases. Moreover, the results corroborate the studies performed by $[5,6,9,10]$ that reported the reduction of the $\gamma_{\mathrm{dmax}}$ upon the increment of the PI.

$$
\begin{aligned}
& \gamma_{d \max }=24.778 \times e^{-0.006 \times L L} ; R^{2}=98.25 \% \\
& \gamma_{d \max }=21.812 \times e^{-0.006 \times P I} ; R^{2}=97.69 \%
\end{aligned}
$$

There is a strong correlation between the $\gamma_{\text {dmax }}$ of fine-grained clay soils and the Atterberg limits because $\mathrm{R}^{2} \geq 80 \%$. Atterberg limits are good predictors of the $\gamma_{\mathrm{dmax}}$. However, the utilization of the specific gravity can improve the accuracy of the $\gamma_{\text {dmax }}$ value like previously proposed by [5-7].

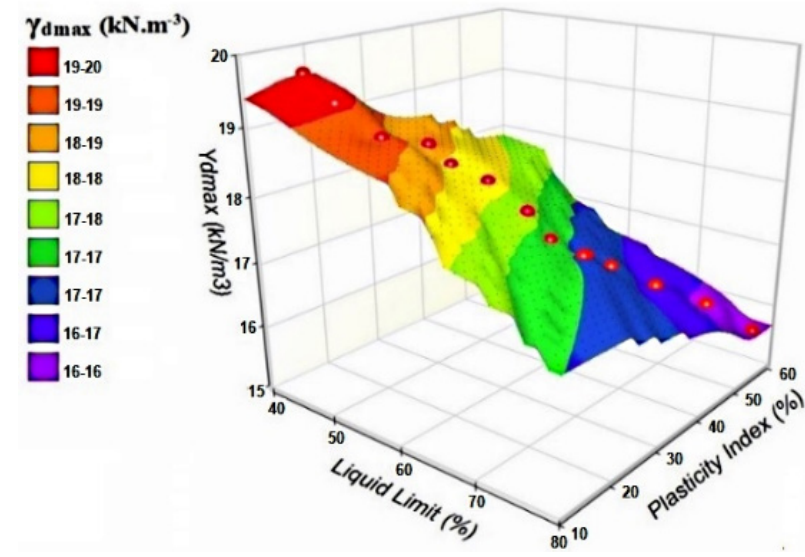

Figure 1 Surface plot: $\gamma_{\mathrm{dmax}}$ vs liquid limit. Plasticity index.

A 3-dimensional representation of the correlation between the $\mathrm{W}_{\mathrm{OP}}$, liquid limit and plasticity index is shown in Figure 2. Also, different colour patterns represent the distribution of the $\mathrm{W}_{\mathrm{OP}}$ values on the surface plot. The blue represents the smaller values. The green, yellow, orange represent the mean values, and the red represents the higher values. Further, the $\mathrm{W}_{\mathrm{OP}}$ value increases when the LL increases. The relationship is an exponential function given in Eq. (35) with $\mathrm{R}^{2}=95.70 \%$. Further, $\mathrm{W}_{\mathrm{OP}}$ values increase when the PI increases. The relationship is an exponential function given in Eq. (36) with $\mathrm{R}^{2}=92.50 \%$. These results are explained through the increment of the Atterberg limits when the clay content increases. Then, the values of $\mathrm{W}_{\mathrm{OP}}$ will increase upon an increment of clay content. These results confirm the outcomes of the investigations carried out by $[2,3,7-9,12,13,14]$ which revealed that the $\mathrm{W}_{\mathrm{OP}}$ increases 
when the LL increases. Moreover, the results are in line with the studies conducted by $[5,6,9,10]$ that reported the increase of the $\mathrm{W}_{\mathrm{OP}}$ upon the increment of the PI.

$W_{O P}=9.568 \times e^{0.0138 \times L L} ; R^{2}=95.70 \%$

$W_{O P}=12.964 \times e^{0.0137 \times P I} ; R^{2}=92.50 \%$

There is a strong correlation between the $\mathrm{W}_{\mathrm{OP}}$ of fine-grained clay soils and the Atterberg limits because $\mathrm{R}^{2} \geq 80 \%$. Atterberg limits are good predictors of the $\mathrm{W}_{\mathrm{OP}}$. Nonetheless, the utilization of the grain size distribution parameters (clay $\%$, sand $\%$, gravel \%) can improve the accuracy of the $\mathrm{W}_{\mathrm{OP}}$ value like previously proposed by $[5,9,10]$.

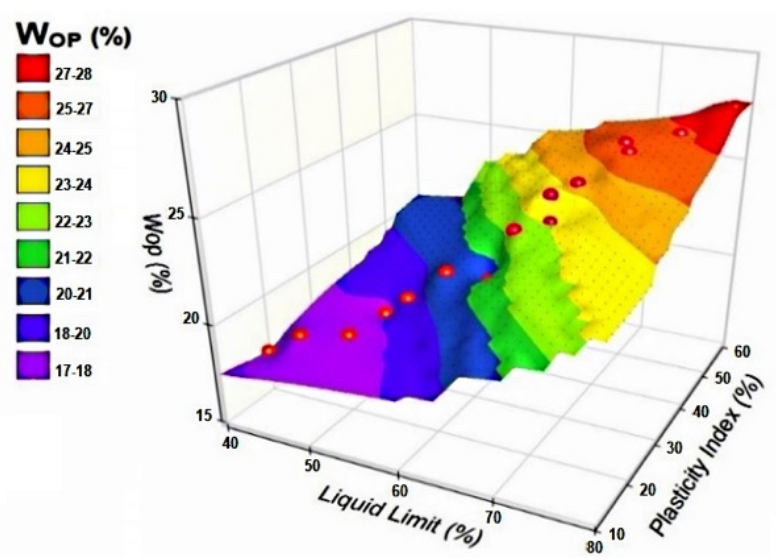

Figure 2 Surface plot: $\mathrm{W}_{\mathrm{OP}}$ vs liquid limit. Plasticity index.

Investigation of the correlations between the compaction features $\left(W_{O P}, \gamma_{d m a x}\right)$, fine-grained content, and sand content

The correlations between the $\mathrm{W}_{\mathrm{OP}}$, fine-grained content, and sand content are shown in Figure 3. The $\mathrm{W}_{\mathrm{OP}}$ value increases when the fine-grained content increases. The correlation is a linear function given in Eq. (37) with $\mathrm{R}^{2}=95.55 \%$. On the other hand, $\mathrm{W}_{\mathrm{OP}}$ values decrease when the sand content increases. The correlation is a linear function given in Eq. (38) with $\mathrm{R}^{2}=80.00 \%$. As the fine-grained content increases, the soil absorbs much more water. As a result, the $\mathrm{W}_{\mathrm{OP}}$ will increase upon fine-grained content increment, and as the sand content increases, the soil absorbs less water. Consequently, the $\mathrm{W}_{\mathrm{OP}}$ reduces upon augmentation of sand content. These results are in line with the outcomes of the investigations carried out by $[7,9,10]$ reported the increase of $\mathrm{W}_{\mathrm{OP}}$ when the fine-grained content increases. Besides, the results corroborate the studies conducted by [7,10] reported the reduction of the $\mathrm{W}_{\mathrm{OP}}$ upon the increment of sand content within the soil material.

$$
\begin{gathered}
W_{O P}=0.283 \times \text { Fine }+4.502 ; R^{2}=95.55 \% \\
W_{O P}=36.097 \times e^{-0.017 \times \text { Sand }} ; R^{2}=80 \%
\end{gathered}
$$


http://wjst.wu.ac.th

The type of correlation between the $\mathrm{W}_{\mathrm{OP}}$, fine-grained content, and sand content is a high strength correlation because $\mathrm{R}^{2} \geq 80$. Therefore, fine-grained content and sand content are valuable covariates of the $\mathrm{W}_{\mathrm{OP}}$.

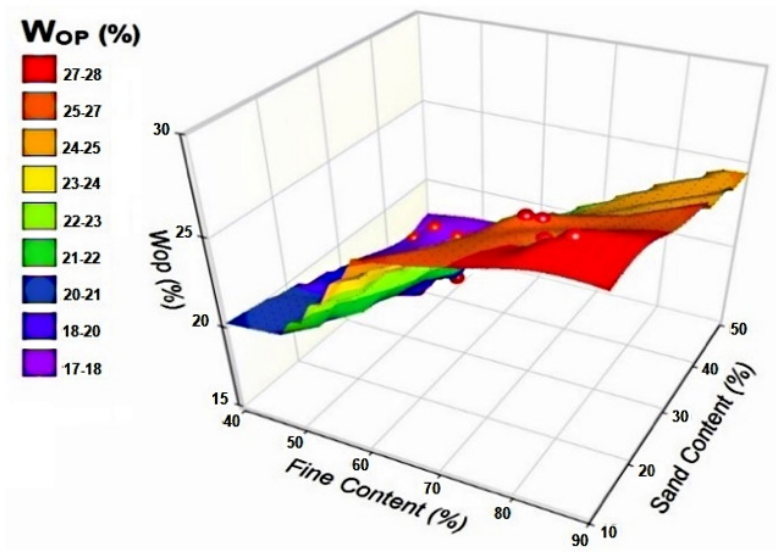

Figure 3 Surface plot: $\mathrm{W}_{\mathrm{OP}}$ vs fine content. Sand content.

Figure 4 depicts the 3-dimensional representation of the relationship between the $\gamma_{\mathrm{dmax}}$, fine-grained content, and sand content. The $\gamma_{\mathrm{dmax}}$ value decreases when the fine-grained content increases. The correlation is a linear function given in Eq. (39) with $\mathrm{R}^{2}=98.23 \%$. On the other hand, $\gamma_{\mathrm{dmax}}$ values increase when the sand content increases. The correlation is a linear function given in Eq. (40) with $\mathrm{R}^{2}=$ $88.67 \%$. As the fine-grained content increases, the soil unit weight per volume decreases. As a result of that, the $\gamma_{\mathrm{dmax}}$ decreases upon the increment of fine-grained content. Besides, the soil unit weight per volume increases as the sand content increases. Therefore, the $\gamma_{\mathrm{dmax}}$ increases upon augmentation of sand content. These results are in line with the outcomes of the investigations carried out by [7,9,10] reported the decrease of $\gamma_{\mathrm{dmax}}$ when the fine-grained content increases. Besides, the results concord with the investigations conducted by $[7,10]$ which reported the augmentation of $\gamma_{\mathrm{dmax}}$ upon the increment of sand content within the soil material.

$$
\begin{aligned}
& \gamma_{d \max }=-0.096 \times \text { Fine }+23.438 ; R^{2}=98.23 \% \\
& \gamma_{d \max }=-0.1289 \times \text { Sand }+13.558 ; R^{2}=88.67 \%
\end{aligned}
$$

The type of relationship between the $\gamma_{\mathrm{dmax}}$, fine-grained content, and sand content is a high strength relationship because $\mathrm{R}^{2} \geq 80 \%$. Therefore, fine-grained content and sand content are relevant predictors of the $\gamma_{\mathrm{dmax}}$. 
http://wjst.wu.ac.th

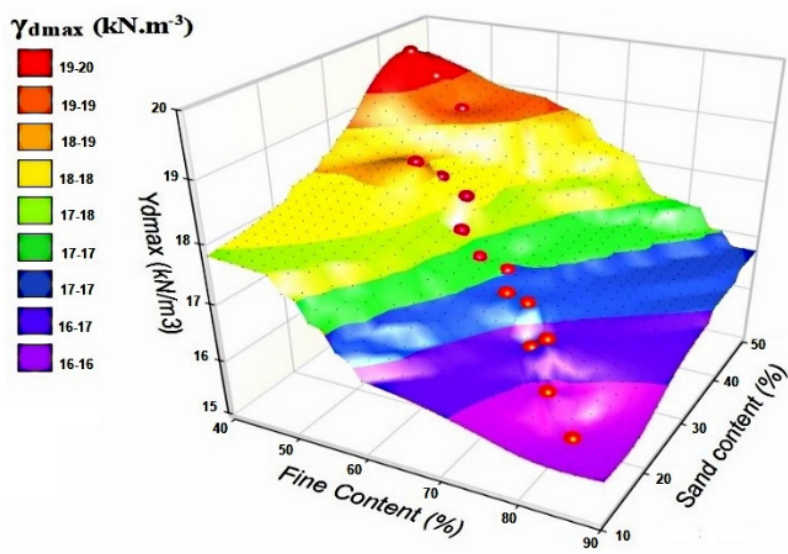

Figure 4 Surface plot: $\gamma_{\mathrm{dmax}}$ vs fine content. Sand content.

\section{Assessment of the correlations between the compaction features $\left(W_{O P}, \gamma_{d m a x}\right)$, gravel content, and specific gravity}

Figure 5 shows a 3-dimensional representation of the correlation between the $\gamma_{\mathrm{dmax}}$, gravel content, and specific gravity. The $\gamma_{\mathrm{dmax}}$ value increases when the gravel content increase. The relationship is a linear function given in Eq. (41) with $\mathrm{R}^{2}=71.14 \%$. On the other hand, $\gamma_{\text {dmax }}$ values decrease when the specific gravity increases. The correlation is an exponential function given in Eq. (42) with $\mathrm{R}^{2}=93.07 \%$. The reduction of $\gamma_{\mathrm{dmax}}$ upon the increment of the specific gravity generates from the fact that at the $\mathrm{W}_{\mathrm{OP}}$, the maximum air void is marginal within the soil particles, and the improvement of the $\gamma_{\mathrm{dmax}}$ upon water addition is no longer possible. The local extremes observed in the surface plot originate from the discrepancies in the correlation $\gamma_{\mathrm{dmax}}$ and gravel content. These results confirm the outcomes of the investigations carried out by $[2,3,7,10]$ which reported that the $\gamma_{\mathrm{dmax}}$ increases when the gravel content increases. Also, the results are in line with the studies conducted by [5-7] which reported the reduction of the $\gamma_{\mathrm{dmax}}$ upon the increment of the specific gravity.

$$
\begin{aligned}
& \gamma_{d \max }=0.209 \times \text { Gravel }+16 ; R^{2}=71.14 \% \\
& \gamma_{d \max }=153.8 \times e^{-0.811 \times G s} ; R^{2}=93.07 \%
\end{aligned}
$$

There is a moderate strength correlation between the $\gamma_{\text {dmax }}$ of gravel content with $\mathrm{R}^{2}<80 \%$. Moreover, there is a high strength correlation between the $\gamma_{\mathrm{dmax}}$ and the specific gravity with $\mathrm{R}^{2}>80 \%$. Thus, the specific gravity is a valuable predictor of the $\gamma_{\mathrm{dmax}} .[7,10]$ reported that the gravel content is a good predictor of $\gamma_{\mathrm{dmax}}$. 
http://wjst.wu.ac.th

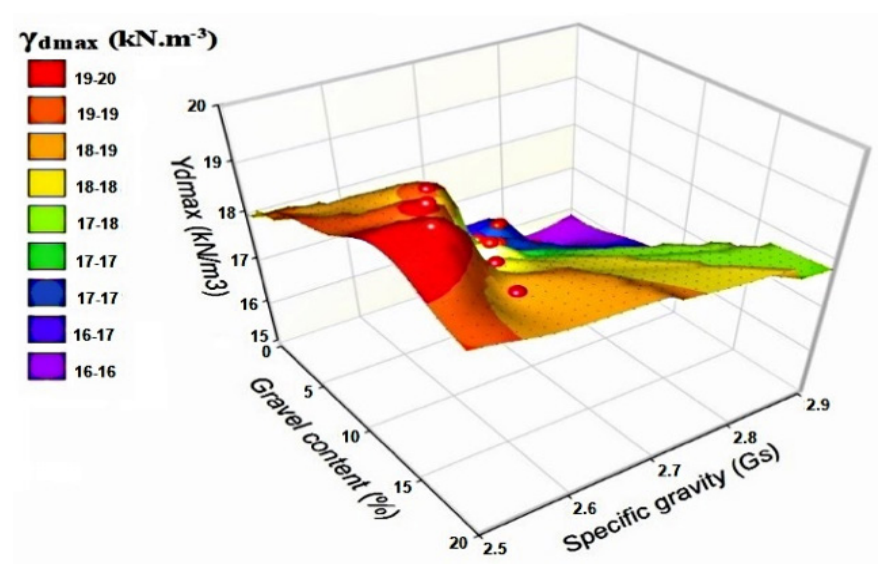

Figure 5 Surface plot: $\gamma_{\mathrm{dmax}}$ vs gravel content. Specific gravity.

Figure 6 shows a 3-dimensional representation of the correlation between the $\mathrm{W}_{\mathrm{OP}}$, gravel content, and specific gravity. The $\mathrm{W}_{\mathrm{OP}}$ value reduces when the gravel content increase. The relationship is a linear function given in Eq. (43) with $\mathrm{R}^{2}=80.59 \%$. Besides, $\mathrm{W}_{\mathrm{OP}}$ values increase when the specific gravity increases. The correlation is a linear function given in Eq. (44) with $\mathrm{R}^{2}=94.39 \%$. The increment of $\mathrm{W}_{\mathrm{OP}}$ upon the augmentation of the specific gravity generates from the fact that at the optimum moisture content, the maximum air void is negligible within the soil grains, and the enhancement of the $\mathrm{W}_{\mathrm{OP}}$ upon water addition is no longer possible. These results confirm the outcomes of the investigations conducted by $[2,3,7,10]$ which reported that the $\mathrm{W}_{\mathrm{OP}}$ reduces when the gravel content increases. Besides, the results are in line with the studies conducted by [5-7] which reported the augmentation of the $\mathrm{W}_{\mathrm{OP}}$ upon the increment of the specific gravity.

$W_{O P}=-0.6667 \times$ Gravel $+26.79 ; R^{2}=80.59 \%$

$W_{O P}=42.914 \times G s-93.166 ; R^{2}=94.39 \%$

Moreover, there is a high strength correlation between the $\mathrm{W}_{\mathrm{OP}}$, gravel content, specific gravity with $\mathrm{R}^{2}>80 \%$. Thus, the gravel content and specific gravity are valuable covariates of the $\mathrm{W}_{\mathrm{OP}}$.

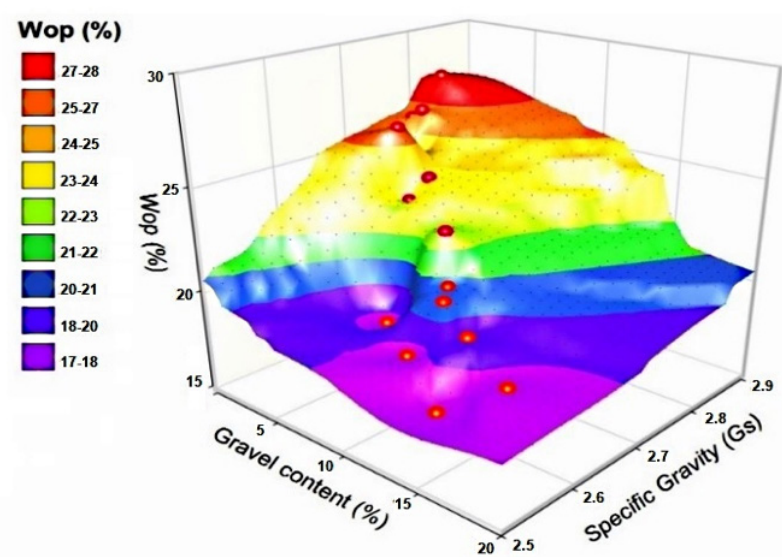

Figure 6 Surface plot: $\mathrm{W}_{\mathrm{OP}}$ vs gravel content. Specific gravity. 
Analysis of the correlations between the compaction features $\left(W_{O P}, \gamma_{d m a x}\right)$, coefficient of curvature and coefficient of uniformity.

Figure 7 depicts the 3-dimensional representation of the relationship between the $\gamma_{\mathrm{dmax}}$, coefficient of curvature $(\mathrm{Cc})$, and coefficient of uniformity $(\mathrm{Cu})$. The $\gamma_{\mathrm{dmax}}$ values increase when the Cc increases. The correlation is a linear function given in Eq. (45) with $\mathrm{R}^{2}=67.23 \%$. Besides, $\gamma_{\mathrm{dmax}}$ values increase when the $\mathrm{Cu}$ increases. The correlation is an exponential function given in Eq. (46) with $\mathrm{R}^{2}=80 \%$. The local extremes observed in the surface plot originate from the discrepancies in the correlation between $\gamma_{\mathrm{dmax}}$ and $\mathrm{Cc}$. The investigation of the correlation between the gradations measure $(\mathrm{Cc}, \mathrm{Cu})$ and $\gamma_{\mathrm{dmax}}$ has not been reported in recent literature.

$$
\begin{aligned}
& \gamma_{\text {dmax }}=1.468 \times C c+16.786 ; R^{2}=67.23 \% \\
& \gamma_{\text {dmax }}=15.558 \times e^{0.0007 \times C u} ; R^{2}=80 \%
\end{aligned}
$$

The type of relationship between the $\gamma_{\mathrm{dmax}}$ and coefficient of uniformity is a high strength relationship because $\mathrm{R}^{2} \geq 80 \%$. Also, a low strength correlation describes the relationship between the $\gamma_{\mathrm{dmax}}$ and $\mathrm{Cc}$ with $\mathrm{R}^{2}<80 \%$. Therefore, the $\mathrm{Cu}$ is a relevant covariate of the $\gamma_{\mathrm{dmax}}$.

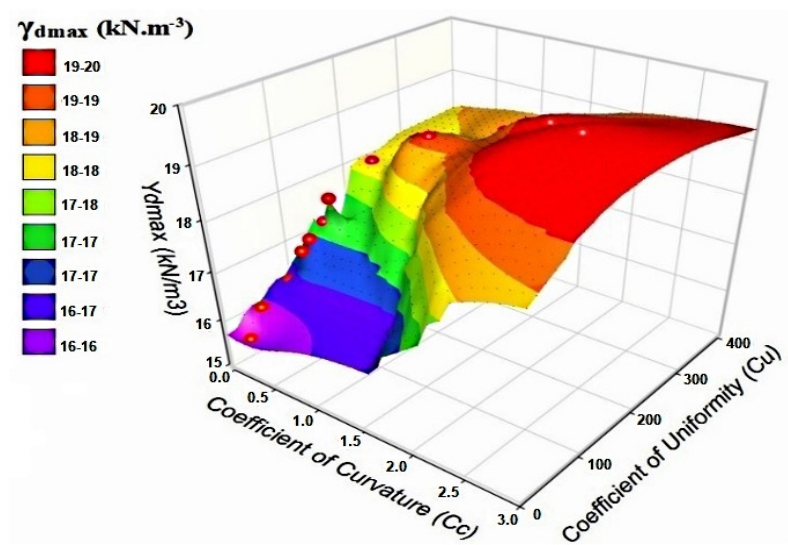

Figure 7 Surface plot: $\gamma_{\mathrm{dmax}}$ vs coefficient of curvature. Coefficient of uniformity.

The correlations between the $\mathrm{W}_{\mathrm{OP}}$, coefficient of curvature $(\mathrm{Cc})$, and coefficient of uniformity $(\mathrm{Cu})$ are shown in Figure 8. The $\mathrm{W}_{\mathrm{OP}}$ values decrease when the $\mathrm{Cc}$ increases. The correlation is an exponential function given in Eq. (47) with $\mathrm{R}^{2}=53.17 \%$. Besides, $\mathrm{W}_{\mathrm{OP}}$ values decrease when the $\mathrm{Cu}$ increases. The correlation is a linear function given in Eq. (48) with $\mathrm{R}^{2}=81.82 \%$. The local extremes observed in the surface plot originate from the discrepancies in the correlation $\mathrm{W}_{\mathrm{OP}}$ and $\mathrm{Cc}$. The assessment of the correlation between the gradations measure $(\mathrm{Cc}, \mathrm{Cu})$ and the $\mathrm{W}_{\mathrm{OP}}$ has not been stated in recent literature.

$W_{O P}=23.77 \times e^{-0.178 \times C c} ; R^{2}=53.17 \%$

$W_{O P}=0.0349 \times C u+28.096 ; R^{2}=81.82 \%$

The type of relationship between the $\mathrm{W}_{\mathrm{OP}}$ and $\mathrm{Cu}$ is a high strength relationship because $\mathrm{R}^{2} \geq 80 \%$. In addition, a low strength correlation describes the relationship between the $\mathrm{W}_{\mathrm{OP}}$ and the Cc with $\mathrm{R}^{2}<80$ $\%$. Therefore, the $\mathrm{Cu}$ is a valuable predictor of the $\mathrm{W}_{\mathrm{OP}}$. 
http://wjst.wu.ac.th

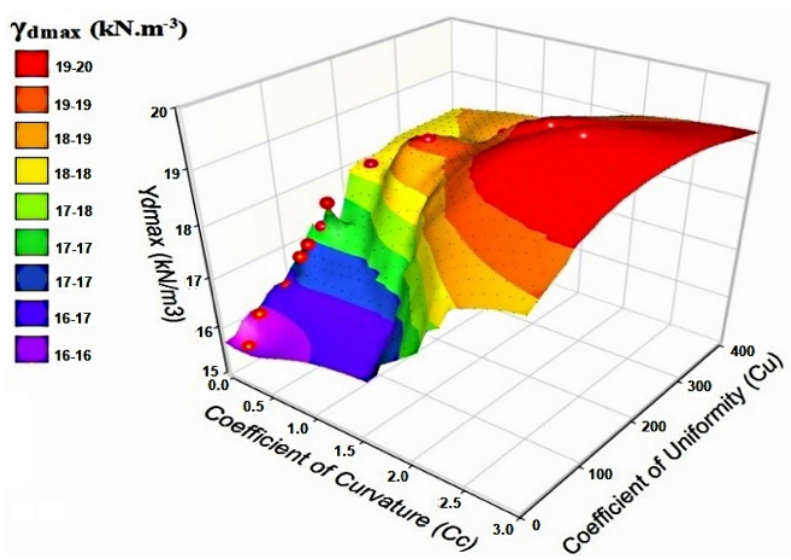

Figure 8 Surface plot: $\mathrm{W}_{\mathrm{OP}}$ vs coefficient of curvature. Coefficient of uniformity.

\section{Models development}

Estimated models

$\mathrm{W}_{\mathrm{OP}}$ and $\gamma_{\mathrm{dmax}}$ are the dependent variables. The independent variables include the liquid limit, finegrained content, sand content, gravel content, coefficient of uniformity and specific gravity. Tables 1 and $\mathbf{2}$ are the correlation matrices utilized to perform the regression analysis using the MINITAB 18 software. The mathematical model to evaluate the $\mathrm{W}_{\mathrm{OP}}$ is described in Eq. (49), and the predictor variables include the liquid limit, fine-grained content, sand content, gravel content, and specific gravity with, respectively the determination coefficient $\xi_{1}, \xi_{2}, \xi_{3}, \xi_{4}, \xi_{5}$ and the intercept $\xi_{0}$. The numerical model to evaluate the $\gamma_{\mathrm{dmax}}$ is given in Eq. (50). The predictor variables include the liquid limit, fine-grained content, sand content, gravel content and specific gravity with respectively the determination coefficient $\mu_{1}, \mu_{2}, \mu_{3}, \mu_{4}$, $\mu_{5}$ and the intercept $\eta_{0}$. Table 3 shows the semi-empirical models summary.

$W_{O P}=+\xi_{0}+\xi_{1} \times L L+\xi_{2} \times F+\xi_{3} \times S+\xi_{4} \times G+\xi_{5} \times G_{S}$

$\gamma_{\text {dmax }}=+\mu_{0}+\mu_{1} \times L L+\mu_{2} \times F+\mu_{3} \times S+\mu_{4} \times G+\mu_{5} \times G_{S}$

where: $\mathrm{W}_{\mathrm{OP}}=$ optimum moisture content, $\%$,

$\gamma_{\mathrm{dmax}}=$ maximum dry unit weight, kN.m-3,

$\mathrm{LL}=$ liquid limit, $\%$,

$\mathrm{F}=$ fine-grained content, $\%$,

$\mathrm{S}=$ sand content, $\%$,

$\mathrm{G}=$ fine-grained, $\%$,

$\mathrm{G}_{\mathrm{s}}=$ specific gravity

$\xi_{0}, \mu_{0}=$ intercepts,

$\xi_{\mathrm{i}}=$ multivariate coefficient, $\mathrm{i}=1, \ldots .5$

$\mu_{\mathrm{i}}=$ multivariate coefficient, $\mathrm{i}=1, \ldots 5$ 
http://wjst.wu.ac.th

Table 3 Models summary.

\begin{tabular}{|c|c|c|c|c|c|c|}
\hline Models & $\begin{array}{c}\mathbf{R}^{2} \\
(\%)\end{array}$ & $\begin{array}{c}\text { Adj-R } \\
(\%)\end{array}$ & $\begin{array}{l}\text { Coefficient of } \\
\text { variation } \\
(\%) \\
\end{array}$ & $\begin{array}{l}\text { Completion } \\
\text { status }\end{array}$ & Intercepts & $\begin{array}{l}\text { Correlation } \\
\text { coefficients }\end{array}$ \\
\hline $\mathrm{W}_{\mathrm{OP}}$ & 97.14 & 95.55 & 3.42 & $\begin{array}{c}\text { Normal } \\
\text { completion }\end{array}$ & $\xi_{0}=+14.5996965388509$ & $\begin{array}{l}\xi_{1}=-0.0522888061151139, \\
\xi 2=+0.621787049592076, \\
\xi 3=+0.274021332880401, \\
\xi 4=+0.0557069587441822, \\
\xi 5=-13.6750680280251 .\end{array}$ \\
\hline$\gamma_{\mathrm{dmax}}$ & 99.19 & 98.74 & 0.77 & $\begin{array}{c}\text { Normal } \\
\text { completion }\end{array}$ & $\mu_{0}=+12.2461227534345$ & $\begin{array}{l}\mu 1=-0.100675570973461, \\
\mu 2=+0.137351578566391, \\
\mu 3=+0.135616808180341, \\
\mu 4=+0.130826737550541, \\
\mu 5=-0.873640016170429\end{array}$ \\
\hline
\end{tabular}

Analysis of the correlations between $W_{O P}$ and the $\gamma_{\mathrm{dmax}}$

Figure 9 describes an exponential correlation between the measured values of $\mathrm{W}_{\mathrm{OP}}$ and predicted values of $\gamma_{\mathrm{dmax}}$ obtained from the developed models. The predicted values of $\gamma_{\mathrm{dmax}}$ decrease when the measured values of $\mathrm{W}_{\mathrm{OP}}$ increase. It can be explained by the fact that at the optimum moisture content, the $\gamma_{\mathrm{d} \max }$ can no longer be increased upon the addition of water and increment of compaction energy. Moreover, marginal discrepancies can also be observed in the scatter plotted data points. Then, it is apparent that there is a strong correlation between the measured values of $\mathrm{W}_{\mathrm{OP}}$ and predicted values of $\gamma_{\mathrm{dmax}}$ with a correlation coefficient $\mathrm{R}^{2}=94.99 \%$. Figure 10 shows an exponential correlation between the measured values of $\gamma_{\mathrm{dmax}}$ and predicted values of $\mathrm{W}_{\mathrm{OP}}$ obtained from the developed models. The predicted values of $\mathrm{W}_{\mathrm{OP}}$ decrease when the measured values of $\gamma_{\mathrm{dmax}}$ increase. It can be explained by the fact that at the optimum moisture content, the $\gamma_{\mathrm{dmax}}$ can no longer be increased upon the addition of water and increment of compaction energy. Likewise, marginal discrepancies can also be observed in the scatter plotted data points. Then, there is a strong correlation between the measured values of $\gamma_{\mathrm{dmax}}$ and predicted values of $W_{O P}$ with a correlation coefficient $\mathrm{R}^{2}=97.39 \%$. Finally, the multicollinearity among dependent variables $\left(\mathrm{W}_{\mathrm{OP}}, \gamma_{\mathrm{dmax}}\right)$ influences the compaction features.

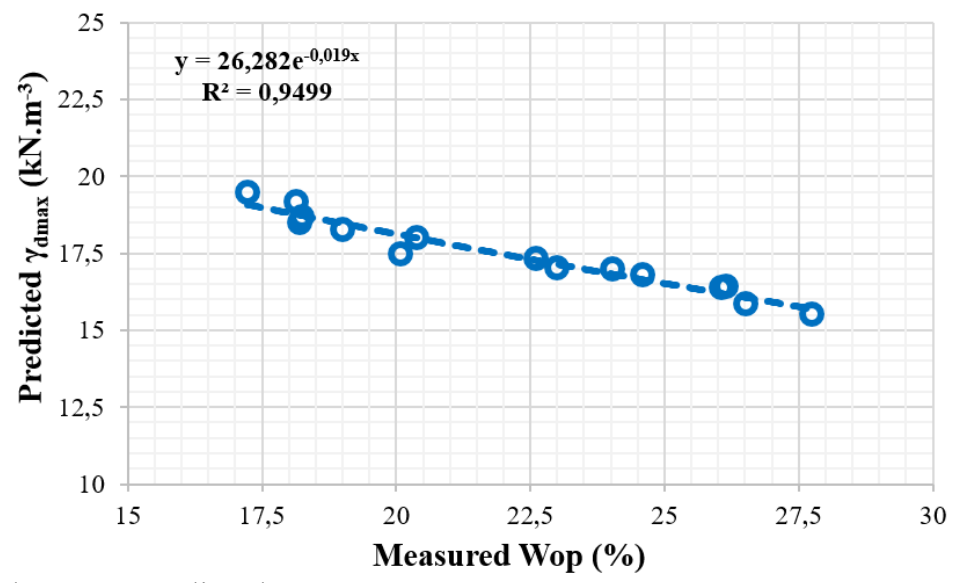

Figure 9 Measured $\mathrm{W}_{\mathrm{OP}}$ vs predicted $\gamma_{\mathrm{dmax}}$. 


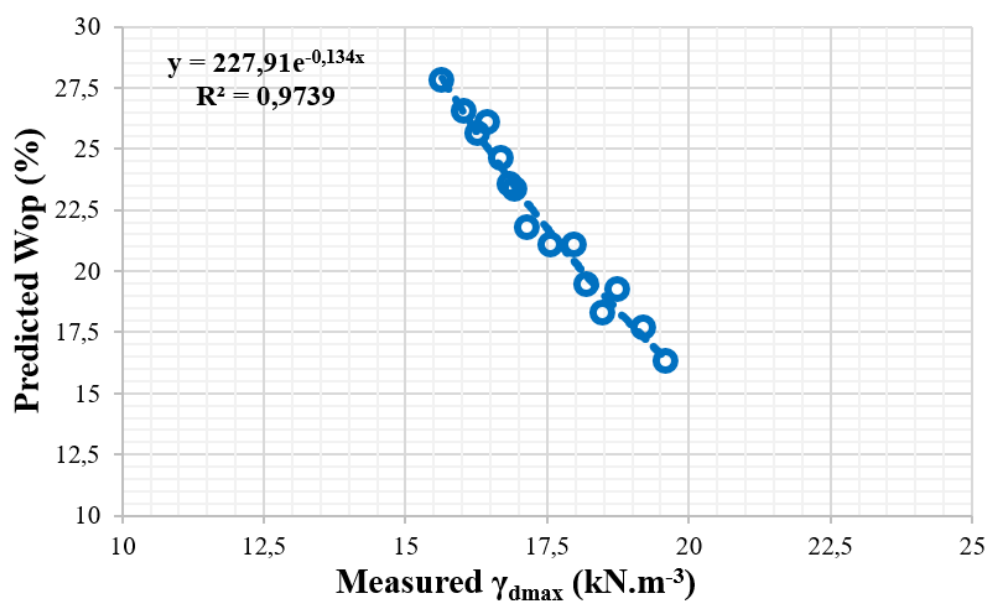

Figure 10 Measured $\gamma_{\mathrm{dmax}}$ vs predicted $\mathrm{W}_{\mathrm{OP}}$.

\section{Models validation}

The validation of the semi-empirical models includes the $p$-value of the term selected for each model, comparing the experimental values with the predicted values, employing a different soil data set and comparing values obtained from the proposed semi-empirical models with the values obtained from other semi-empirical models proposed by $[10,13,14]$. The primary criteria to select the relevant independent variable is the probability value ( $p$-value). If $p$-value for the coefficient of the predictor variable is higher than 0.05 , the coefficient is considered as 0 . The independent variable is viewed as insignificant and excluded from the model. Table 4 shows the $p$-values of each model predictors, and the $p$-value of the selected predictor variable is smaller than 0.05 .

Table $4 p$-values for choosing the terms for predictive models.

\begin{tabular}{|c|c|c|c|}
\hline \multicolumn{2}{|c|}{$\gamma_{\mathrm{dmax}}\left(\mathbf{k N} \cdot \mathrm{m}^{-3}\right)$} & \multicolumn{2}{|c|}{$W_{O P}(\%)$} \\
\hline Terms & $p$-value & Terms & $p$-value \\
\hline LL (\%) & 0.000 & LL (\%) & 0.000 \\
\hline PI (\%) & 0.045 & PI (\%) & 0.037 \\
\hline $\operatorname{PL}(\%)$ & 0.063 & $\operatorname{PL}(\%)$ & 0.088 \\
\hline $\mathrm{F}(\%)$ & 0.000 & $\mathrm{~F}(\%)$ & 0.001 \\
\hline $\mathrm{S}(\%)$ & 0.011 & S (\%) & 0.038 \\
\hline $\mathrm{G}(\%)$ & 0.032 & $\mathrm{G}(\%)$ & 0.025 \\
\hline $\mathrm{C}_{\mathrm{C}}$ & 0.331 & $\mathrm{C}_{\mathrm{C}}$ & 0.452 \\
\hline $\mathrm{C}_{\mathrm{u}}$ & 0.016 & $\mathrm{C}_{\mathrm{u}}$ & 0.022 \\
\hline $\mathrm{G}_{\mathrm{s}}$ & 0.000 & $\mathrm{G}_{\mathrm{s}}$ & 0.000 \\
\hline
\end{tabular}

Figure 11 shows the comparison of the $\mathrm{W}_{\mathrm{OP}}$ experimental values obtained from the lab compaction test and the $\mathrm{W}_{\mathrm{OP}}$ values obtained from predictive models. The scatter plot follows the trend line 1:1 with $\mathrm{R}^{2}=97.62 \%$. Therefore, there is a high strength correlation between the experimental and the predicted values of $\mathrm{W}_{\mathrm{OP}}$. Figure 12 displays the comparison of the $\gamma_{\mathrm{dmax}}$ experimental values obtained from the lab compaction test and the results obtained from the predictive models. The scatter plot follows the trend line $1: 1$ with $\mathrm{R}^{2}=99.28 \%$. Hence, there is a high strength correlation between the predicted and the experimental values of $\gamma_{\mathrm{dmax}}$. 


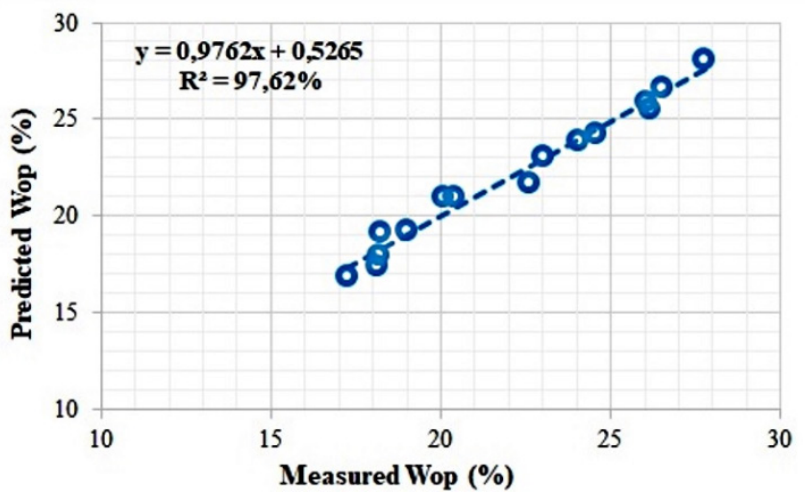

Figure 11 Predicted $\mathrm{W}_{\mathrm{OP}}$ vs Measured $\mathrm{W}_{\mathrm{OP}}$.

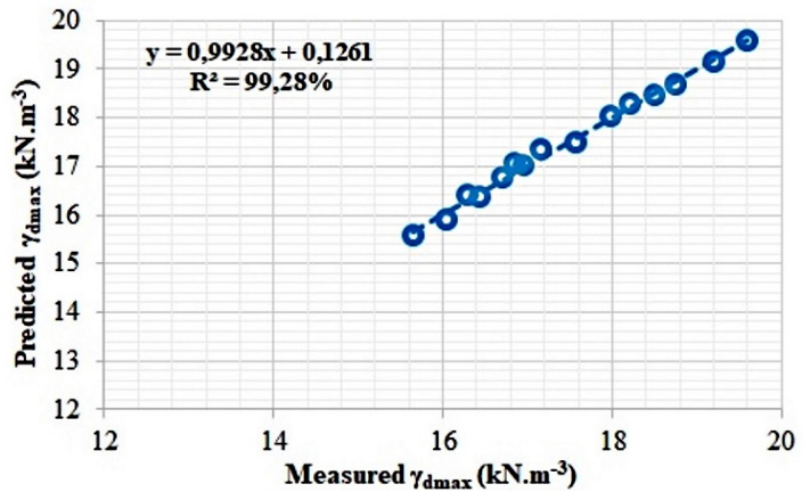

Figure 12 Predicted $\gamma_{\mathrm{dmax}}$ vs measured $\gamma_{\mathrm{dmax}}$.

Table 5 Validation of compaction features models.

\begin{tabular}{|c|c|c|c|c|c|c|c|}
\hline \multicolumn{4}{|c|}{$\begin{array}{c}\text { Optimum water content } \\
\left(\mathbf{W}_{\text {OP }} \%\right)\end{array}$} & \multicolumn{4}{|c|}{$\begin{array}{c}\text { Maximum dry unit weight } \\
\gamma_{\text {dmax }}\left(\mathrm{kN} \cdot \mathrm{m}^{-3}\right)\end{array}$} \\
\hline $\begin{array}{c}\text { Measured } \\
\text { W }_{\text {OP }}\end{array}$ & $\begin{array}{c}\text { Predicted } \\
\text { W }_{\text {OP }}\end{array}$ & $\begin{array}{l}\text { Absolute } \\
\text { Error } \\
(\mathrm{AE}) \\
\end{array}$ & $\begin{array}{c}\text { Standard Error } \\
\text { of Predicted } \\
\text { (SEP) } \\
\end{array}$ & $\begin{array}{c}\text { Measured } \\
\gamma_{\mathrm{dmax}}\end{array}$ & $\begin{array}{c}\text { Predicted } \\
\gamma_{\mathrm{dmax}}\end{array}$ & $\begin{array}{l}\text { Absolute } \\
\text { Error } \\
\text { (AE) } \\
\end{array}$ & $\begin{array}{c}\text { Standard Error } \\
\text { of Predicted } \\
\text { (SEP) } \\
\end{array}$ \\
\hline 18.2 & 18.25728 & 0.05728 & 0.9320374 & 18.5 & 18.48636 & 0.01364 & 0.1656864 \\
\hline 19.01 & 19.42636 & 0.41636 & 0.8527382 & 18.21 & 18.28459 & 0.07459 & 0.1515895 \\
\hline 20.38 & 20.98998 & 0.60998 & 0.9004595 & 17.99 & 18.00741 & 0.01741 & 0.1600728 \\
\hline 20.07 & 21.03164 & 0.96164 & 0.9111131 & 17.58 & 17.48148 & 0.09852 & 0.1619667 \\
\hline 22.61 & 21.73959 & 0.87041 & 0.890292 & 17.16 & 17.32449 & 0.16449 & 0.1582654 \\
\hline 23 & 23.28331 & 0.28331 & 0.8774942 & 16.95 & 17.02626 & 0.07626 & 0.1559903 \\
\hline 24.03 & 23.52879 & 0.50121 & 0.8743505 & 16.85 & 16.98302 & 0.13302 & 0,1554315 \\
\hline 24.58 & 24.57108 & 0.00892 & 0.8533756 & 16.71 & 16.80579 & 0.09579 & 0.1517028 \\
\hline 26.05 & 26.025 & 0.025 & 0.8614653 & 16.45 & 16.38722 & 0.06278 & 0.1531409 \\
\hline 26.14 & 25.60787 & 0.53213 & 1.002494 & 16.29 & 16.41774 & 0.12774 & 0.1782113 \\
\hline 26.52 & 26.50245 & 0.01755 & 0.9077139 & 16.05 & 15.86116 & 0.18884 & 0.1613625 \\
\hline 27.75 & 27.79116 & 0.04116 & 0.9306315 & 15.65 & 15.52676 & 0.12324 & 0.1654365 \\
\hline 17.23 & 16.27339 & 0.95661 & 0.8654909 & 19.6 & 19.4951 & 0.1049 & 0.1538566 \\
\hline 18.13 & 17.61067 & 0.51933 & 0.8671499 & 19.2 & 19.17003 & 0.02997 & 0.1541515 \\
\hline 18.24 & 19.20144 & 0.96144 & 0.8996686 & 18.76 & 18.69257 & 0.06743 & 0.1599322 \\
\hline
\end{tabular}


The absolute error (AE) is the absolute difference between the measured and the predicted values. Table 5 shows AE values between the measured and the predicted values of the compaction features $\left(\mathrm{W}_{\mathrm{OP}}, \gamma_{\mathrm{dmax}}\right)$. The maximal AE value of $\gamma_{\mathrm{dmax}}$ is in the order of 0.18884 , and the maximal AE value of $\mathrm{W}_{\mathrm{OP}}$ is in the order of 0.96164. Moreover, Table 5 shows the Standard Error of Predicted (SEP) values of compaction features $\left(\mathrm{W}_{\mathrm{OP}}, \gamma_{\mathrm{dmax}}\right)$. The maximal SEP value of $\gamma_{\mathrm{dmax}}$ is in the order of 0.1782113 , and the maximal SEP value of Wop is in the order of 1.002494. The predicted and the measured values are very closed, and the ranges of AE and SEP are acceptacle because $\leq 1$. Therefore, the proposed models can be utilized to predict the compaction features with acceptable precision.

The validation of the proposed models is also conducted using different soil data sets to verify the maximum absolute error of cross-validation. The experimental soil data sets given by Kok Shien et al. [10] in Table 6 are selected because these data exhibit all the soil parameters in the models proposed in this research work. Table 7 shows the absolute error (AE) values between measured and predicted values of compaction features $\left(\mathrm{W}_{\mathrm{OP}}, \gamma_{\mathrm{dmax}}\right)$ for the data set given by Kok Shien et al. [10]. Soils 1, 2, 4, 5, 7, 8, 9 validated the predicted values of Wop with $\mathrm{AE}<1$. Nevertheless, soils 3, 6 failed to validate the predicted values of $\mathrm{W}_{\mathrm{OP}}$ with $\mathrm{AE}>1$. On the other hand, soils 1, 2, 3, 4, 5, 6,7, 8 validated the predicted values of $\gamma_{\mathrm{dmax}}$ with $\mathrm{AE}<1$. Likewise, soil 9 fails to validate the predicted values of $\gamma_{\mathrm{dmax}}$ with $\mathrm{AE}>1.15$ soil specimens have validated the predicted models, and 3 have failed. The soil specimens used in this study to develop the models are high plastic clay and low plastic clay, but the soil materials given by Kok Shien et al. [10] are low plastic silt and high plastic silt. Fondjo and Dzogbewu [22] reported that the discrepancies observed between predicted values and experimental values may also be due to the inherent approximated approach in multivariate analysis.

Table 6 Experimental datas, Kok Shien et al. [10]

\begin{tabular}{|c|c|c|c|c|c|c|c|c|c|c|}
\hline $\begin{array}{c}\text { Soil } \\
\text { Designation }\end{array}$ & $\begin{array}{c}\text { Gravel } \\
(\%)\end{array}$ & $\begin{array}{l}\text { Sand } \\
(\%)\end{array}$ & $\begin{array}{l}\text { Silt } \\
(\%)\end{array}$ & $\begin{array}{l}\text { Clay } \\
(\%)\end{array}$ & $\begin{array}{c}\text { Fines } \\
(\%)\end{array}$ & $\begin{array}{c}\text { Liquid } \\
\text { Limit } \\
(\%)\end{array}$ & $\begin{array}{c}\text { Plastic } \\
\text { Limit } \\
(\%)\end{array}$ & $\begin{array}{c}\text { Specific } \\
\text { gravity } \\
\text { (Gs) }\end{array}$ & $\begin{array}{l}\text { Optimum } \\
\text { water } \\
\text { content } \\
(\%)\end{array}$ & 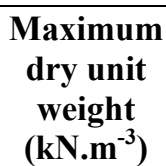 \\
\hline Soil 1 & 7 & 39 & 41 & 13 & 54 & 43 & 27 & 2.55 & 18 & 16.6 \\
\hline Soil 2 & 9 & 46 & 36 & 9 & 45 & 53 & 34 & 2.45 & 24 & 14.7 \\
\hline Soil 3 & 3 & 28 & 50 & 19 & 69 & 51 & 33 & 2.56 & 24 & 14.8 \\
\hline Soil 4 & 1 & 8 & 64 & 27 & 91 & 47 & 30 & 2.57 & 19.5 & 16.0 \\
\hline Soil 5 & 20 & 46 & 31 & 3 & 34 & 44 & 28 & 2.56 & 14 & 17.2 \\
\hline Soil 6 & 0 & 25 & 40 & 35 & 75 & 46 & 29 & 2.54 & 17 & 15.7 \\
\hline Soil 7 & 10 & 46 & 32 & 12 & 44 & 42 & 26 & 2.55 & 17 & 16.5 \\
\hline Soil 8 & 26 & 30 & 26 & 18 & 44 & 43 & 28 & 2.58 & 14.5 & 17.2 \\
\hline Soil 9 & 20 & 46 & 23 & 11 & 34 & 41 & 26 & 2.60 & 13.5 & 17.4 \\
\hline
\end{tabular}

Figure 13 describes the correlations between the predicted and the measured values of $\mathrm{W}_{\mathrm{OP}}$ obtained from the model developed in this study and the $\mathrm{W}_{\mathrm{OP}}$ values obtained from the model previously proposed by Kok Shien et al. [10]. The proposed model in this research work gives more accurate values with $\mathrm{R}^{2}=97.62 \%$ than the model developed by Kok Shien et al. [10] with $\mathrm{R}^{2}=93.92 \%$. Furthermore, Figure 14 shows the relationships between the predicted and the measured values $\gamma_{\mathrm{dmax}}$ obtained from the numerical model proposed in this research work and the $\gamma_{\mathrm{dmax}}$ values obtained from the model developed by Kok Shien et al. [10]. The proposed model in this research work gives accurate values with $\mathrm{R}^{2}=$ $99.28 \%$ than the model previously developed by Kok Shien et al. [10] with $\mathrm{R}^{2}=9.13 \%$. However, Figures 13 and 14 shows some discrepancies between compaction features predicted from proposed models and ones by Kok Shien et al. [10], that can be explained by some differences in properties. Soil samples used in this study are described as follows: Fines content ranges between 49.50 and $74.78 \%$. The LL ranges between 40.29 and $78.94 \%$, and the PL ranges between 17.83 and $56.68 \%$. $\mathrm{W}_{\mathrm{OP}}$ values are 
between 18.20 and $27.75 \%$. The $\gamma_{\mathrm{dmax}}$ values are between 15.65 to $19.60 \mathrm{kN} \cdot \mathrm{m}^{-3}$. The specific gravity values are between 2.55 and 2.78. These soils are low plastic clay and high plastic clay. On the other hand, Kok Shien et al. [10] used samples with the following properties: Fines content ranges between 34 and $91 \%$. The LL ranges between 43 and $52 \%$, and the PL ranges between 26 and $34 \%$. the $\mathrm{W}_{\mathrm{OP}}$ values are between 13.5 and $24 \%$. The $\gamma_{\mathrm{dmax}}$ values are between 14.7 to $17.4 \mathrm{kN} \cdot \mathrm{m}^{-3}$. The specific gravity values are between 2.45 and 2.60. These soils are low plastic silt and high plastic silt.

Table 7 Validation of compaction features models using data given by Kok Shien et al. [10]

\begin{tabular}{ccccccc}
\hline \multirow{2}{*}{$\begin{array}{c}\text { Soil } \\
\text { Designation }\end{array}$} & \multicolumn{3}{c}{$\begin{array}{c}\text { Optimum water content } \\
\left(\mathbf{W}_{\mathbf{O P}} \mathbf{\%}\right)\end{array}$} & \multicolumn{3}{c}{$\begin{array}{c}\text { Maximum dry unit weight } \\
\gamma_{\text {dmax }}\left(\mathbf{k N . m}^{-3}\right)\end{array}$} \\
\cline { 2 - 7 } & Measured & Predicted & $\begin{array}{c}\text { Absolute } \\
\text { Error (AE) }\end{array}$ & Measured & Predicted & $\begin{array}{c}\text { Absolute } \\
\text { Error (AE) }\end{array}$ \\
\hline Soil 1 & 18 & 17.86 & 0.14 & 16.60 & 17.30 & 0.7 \\
Soil 2 & 24 & 23.47 & 0.53 & 14.70 & 14.54 & 0.16 \\
Soil 3 & 24 & 21.31 & 2.69 & 14.80 & 15.78 & 0.98 \\
Soil 4 & 19.5 & 19.33 & 0.17 & 16.00 & 15.60 & 0.4 \\
Soil 5 & 14 & 14.98 & 0.98 & 17.20 & 17.65 & 0.45 \\
Soil 6 & 17 & 20.06 & 3.06 & 15.70 & 16.04 & 0.34 \\
Soil 7 & 17 & 17.14 & 0.14 & 16.50 & 16.77 & 0.27 \\
Soil 8 & 14.5 & 13.85 & 0.65 & 17.20 & 17.40 & 0.20 \\
Soil 9 & 13.5 & 14.16 & 0.66 & 17.40 & 18.74 & 1.34 \\
\hline
\end{tabular}

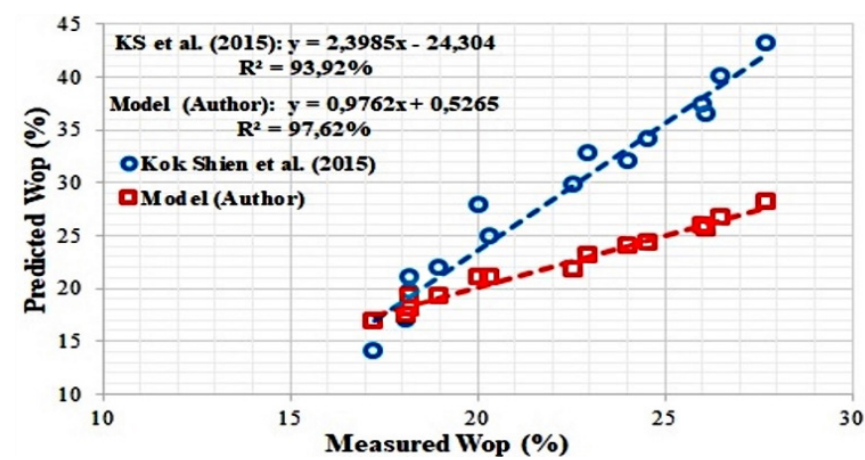

Figure 13 Measured $\mathrm{W}_{\mathrm{OP}}$ vs predictive $\mathrm{W}_{\mathrm{OP}}$ by Kok Shien et al. [10].

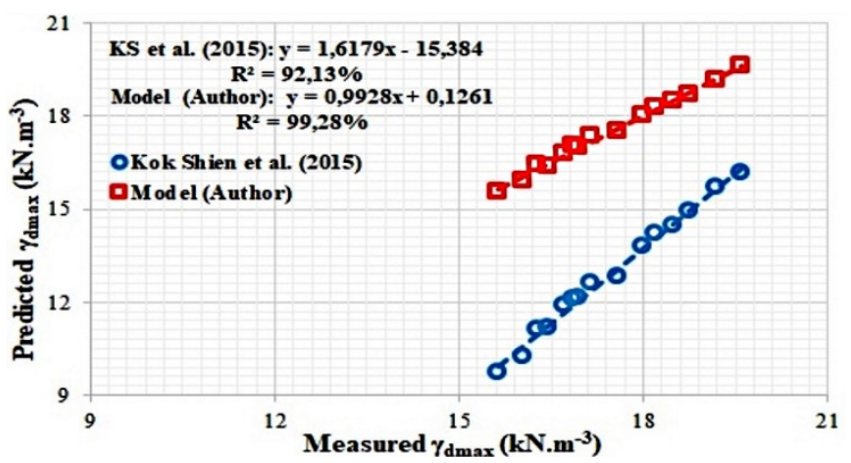

Figure 14 Measured $\gamma_{\mathrm{dmax}}$ vs predictive $\gamma_{\mathrm{d} \max }$ by Kok Shien et al. [10]. 
Figure 15 shows the relationships between the predicted and measured values of $\mathrm{W}_{\mathrm{OP}}$ obtained from the predictive model proposed in this study and the $\mathrm{W}_{\mathrm{OP}}$ values obtained from the model previously developed by Firomsa and Quezon [13]. The proposed model in this study displays more accurate values with $\mathrm{R}^{2}=97.62 \%$ than the model developed by Firomsa and Quezon [13] with $\mathrm{R}^{2}=94.39 \%$. Moreover, Figures 16 describes the correlations between the predicted and the measured values of $\gamma_{\mathrm{dmax}}$ obtained from the model developed in this study and the $\mathrm{W}_{\mathrm{OP}}$ and $\gamma_{\mathrm{dmax}}$ values obtained from the predictive model proposed by Firomsa and Quezon [13]. The proposed model in this research work gives accurate values with $\mathrm{R}^{2}=99.28 \%$ than the model developed by Firomsa and Quezon [13] with $\mathrm{R}^{2}=92 \%$. Nonetheless, Figures 15 and 16 shows some discrepancies between compaction features predicted from developed models and ones by Firomsa and Quezon [13] that can be explained by some properties discrepancies. Soil samples used in this study are described as follows: Fines content ranges between 49.50 and 74.78 $\%$. The LL ranges between 40.29 and $78.94 \%$, and the PL ranges between 17.83 and $56.68 \%$. $\mathrm{W}_{\mathrm{OP}}$ values are between 18.20 and $27.75 \%$. The $\gamma_{\mathrm{dmax}}$ values are between 15.65 to $19.60 \mathrm{kN} . \mathrm{m}^{-3}$. The specific gravity values are between 2.55 and 2.78 . These soils are low plastic clay and high plastic clay. On the other hand, Firomsa and Quezon [13] used samples with the following properties: The LL values between 76 and $103 \%$. The PL values between 33 and $59 \%$. The $\gamma_{\text {dmax }}$ values are between 12.6 and 14.1 kN.m ${ }^{-3}$ when the $\mathrm{W}_{\mathrm{OP}}$ values are between 32 and $40 \%$. The specific gravity values are between 2.1 to 2.80 . The samples exhibit the feature of high plastic clayey soils. Moreover, these soil samples display a swelling potential with LL $>70 \%$.

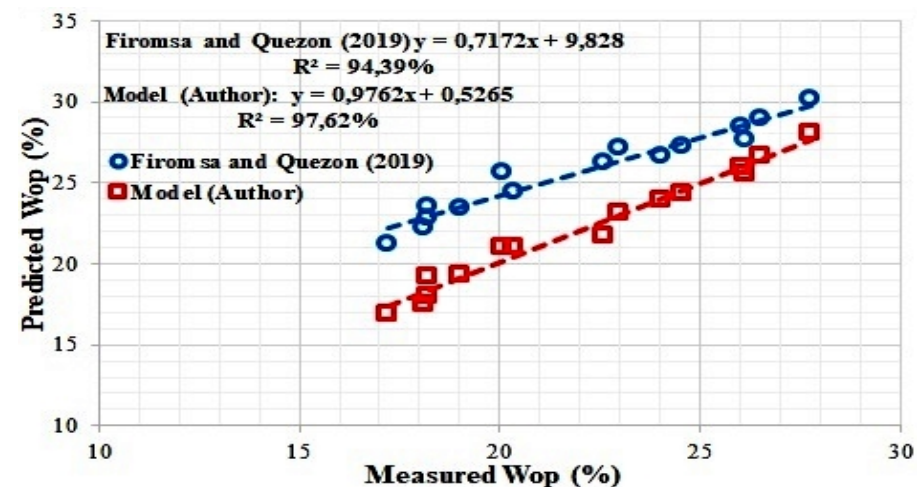

Figure 15 Measured $\mathrm{W}_{\mathrm{OP}}$ vs predictive $\mathrm{W}_{\mathrm{OP}}$ by Firomsa and Quezon [13].

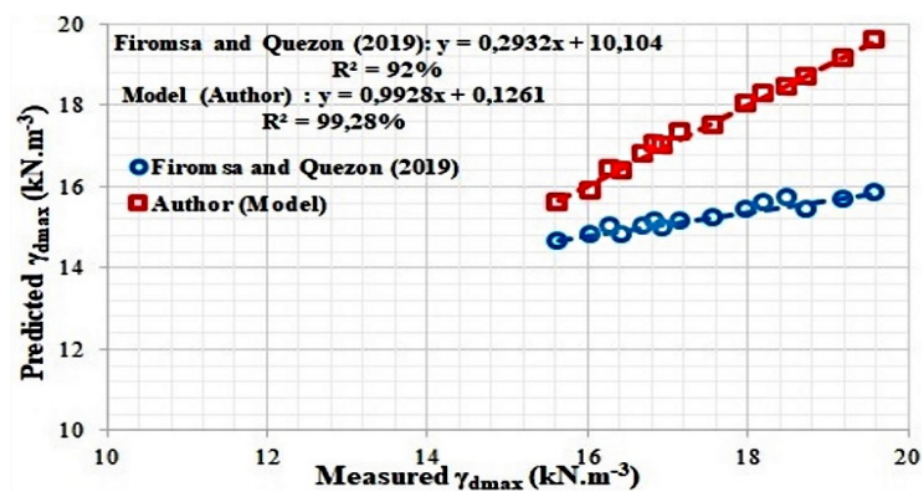

Figure 16 Measured $\gamma_{\mathrm{dmax}}$ vs predictive $\gamma_{\mathrm{dmax}}$ by Firomsa and Quezon [13]. 
Figure 17 describes the relationships between the predicted and measured values of $\mathrm{W}_{\mathrm{OP}}$ obtained from the semi-empirical model developed in this study and $\mathrm{W}_{\mathrm{OP}}$ values obtained from the predictive model precedently proposed by Hussain and Atalar [14]. The proposed model in this research work gives accurate values with $\mathrm{R}^{2}=97.62 \%$ than the model developed by [14] with $\mathrm{R}^{2}=94.92 \%$. Besides, Figure 18 shows the correlations between the predicted and the measured values of $\gamma_{\text {dmax }}$ obtained from the numerical model proposed in this research work and the $\gamma_{\mathrm{dmax}}$ values obtained from the model developed by Hussain and Atalar [14]. The proposed model in this study displays accurate values with $\mathrm{R}^{2}=99.28 \%$ than the model developed by [14] with $\mathrm{R}^{2}=94.61 \%$. These soils are low plastic clay and high plastic clay. However, Figures 17 and 18 shows some discrepancies between compaction features predicted from proposed regressions and ones by Hussain and Atalar [14] that can be justified by some parameters differences. Soil samples used in this study are described as follows: Fines content ranges between 49.50 and $74.78 \%$. LL ranges between 40.29 and $78.94 \%$, and PL ranges between 17.83 and $56.68 \%$. $\mathrm{W}_{\mathrm{OP}}$ values are between 18.20 and $27.75 \%$. The $\gamma_{\mathrm{dmax}}$ values are between $15.65 \mathrm{k}$ to $19.60 \mathrm{kN} . \mathrm{m}^{-3}$. The specific gravity values are between 2.55 and 2.78. On the other hand, Hussain and Atalar [14] used samples with the following properties: LL are between 43.2 and $76.8 \%$. PL values are between 18 to $25.7 \%$. The $\gamma_{\text {dmax }}$ values are between 15.63 and $19.25 \mathrm{kN} . \mathrm{m}^{-3}$. $\mathrm{W}_{\mathrm{OP}}$ values are between 15.5 and $22.50 \%$.

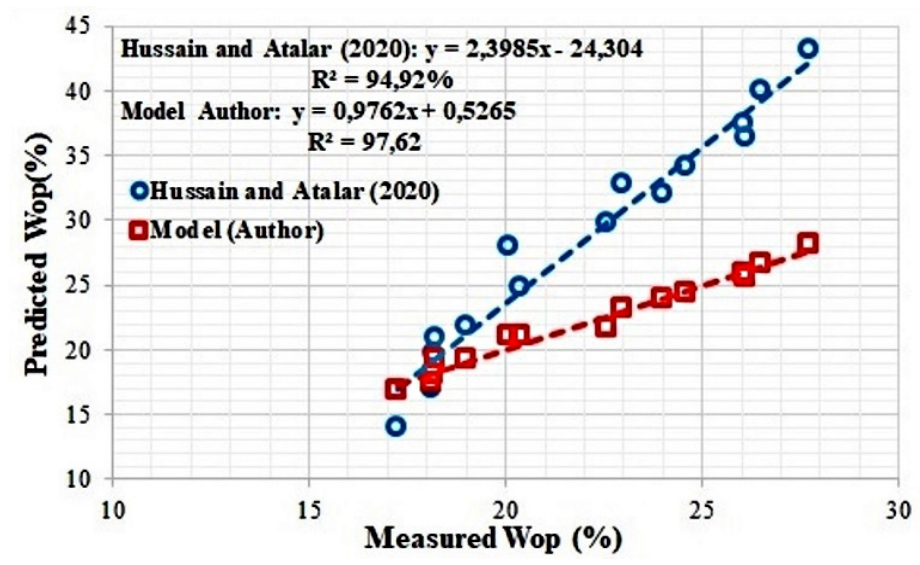

Figure 17 Measured $\mathrm{W}_{\mathrm{OP}}$ vs predictive $\mathrm{W}_{\mathrm{OP}}$ by Hussain and Atalar [14].

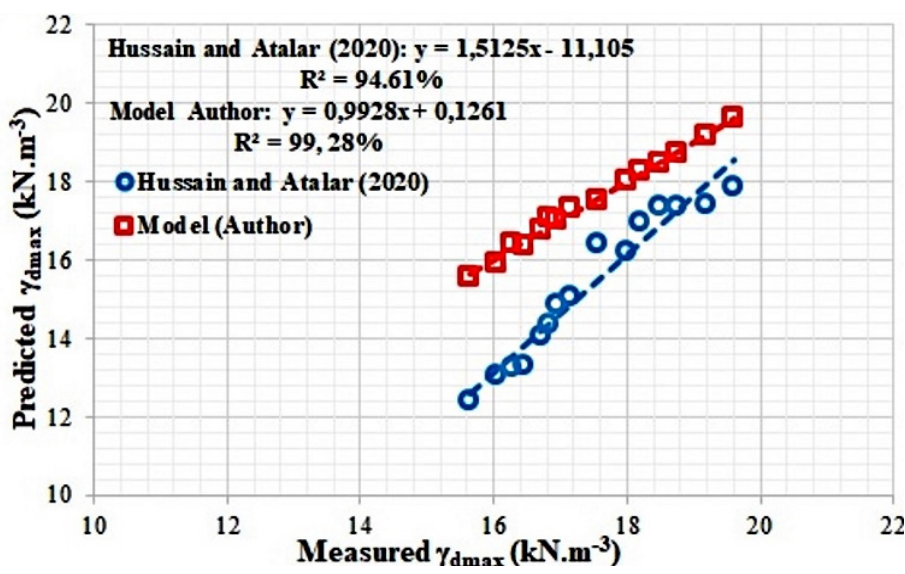

Figure 18 Measured $\gamma_{\mathrm{dmax}}$ vs predictive $\gamma_{\mathrm{dmax}}$ by Hussain and Atalar [14]. 
http://wjst.wu.ac.th

\section{Conclusions}

The study aims to develop numerical predictive models of compaction features of fine-grained clay soils. The results revealed that the $\mathrm{W}_{\mathrm{OP}}$ increases when Atterberg limits, fine-grained content, specific gravity increase. On the other hand, the $\mathrm{W}_{\mathrm{OP}}$ decreases when the sand content, gravel content, $\mathrm{Cc}$ and $\mathrm{Cu}$ increase. Besides, the $\gamma_{\mathrm{dmax}}$ reduces when the Atterberg limit, fine-grained content decrease. Nonetheless, the $\gamma_{\mathrm{dmax}}$ increases when the sand content, gravel content, $\mathrm{Cc}$ and $\mathrm{Cu}$ increase. The soil properties that influence the compaction features include the Atterberg limits, grain size distribution, gradation parameters, and the specific gravity. Numerical models to predict the compaction features developed in this research work gives more accurate predicted values than models recently proposed by $[10,13,14]$. It can be explained by some differences in soil material and the relevant number of predictors that include the Atterberg limits, grain size distribution, and specific gravity, unlike previous models. The proposed models can predict the $\gamma_{\mathrm{dmax}}$ and $\mathrm{W}_{\mathrm{OP}}$ of fine-grained clay soils with acceptable precision. These models can be used in routine engineering practice applications to determine the compaction features. The compaction test is alleviated, and the processing time is reduced. The results of this research work can be utilized for geotechnical modeling of compacted fine-grained clay soils as a continuum material with the application finite element method.

\section{References}

[1] A Sridharan and HB Nagaraj. Plastic limit and compaction characteristics of fine grained soils. Proc. Inst. Civ. Eng. Ground Improv. 2005; 9, 17-22.

[2] R Mohd and G Che. 2005, Correlation regression between soil compaction parameters and atterberg limits. Bachelor Thesis. Universiti Teknologi Malaysia, Johor, Malaysia.

[3] K Faizah. 2005, Estimation of compaction parameters based on atterberg limits. Master Thesis. Universiti Teknologi Malaysia, Johor, Malaysia.

[4] O Sivrikaya, E Togrol and C Kayadelen. Estimating compaction behavior of fine-grained soils based on compaction energy. Can. Geotech. J. 2008; 45, 751-67.

[5] S Noor, R Chitra and M Gupta. Estimation of proctor properties of compacted fine grained soils from index and physical properties. Int. J. Earth Sci. Eng. 2011; 4, 147-50.

[6] A Singh and S Noor. Soil compression index prediction model for fine grained soils. Int. J. Innovat. Eng. Tech. 2012; 14, 34-7.

[7] N Naderi, P Roshani, MZ Samani and MA Tutunchian. Application of genetic programming for estimation of soil compaction parameters. Appl. Mech. Mater. 2012; 147, 70-4.

[8] K Đoković, D Rakić and M Ljubojev. Estimation of soil compaction parameters based on the atterberg limits. Min. Metall. Eng. Bor 2013; 4, 1-16.

[9] A Idris, MI Waziri, AY Abdulfatah and M Umar. Modelling and prediction of compaction parameters based on atterberg limits and clay content. J. Eng. Tech. 2014; 9, 24-7.

[10] NGK Shien, YM Chew, MH Osman and SK Mohamad Ghazali. Estimating maximum dry density and optimum moisture content of compacted soils. In: Proceedings of the International Conference on Advances in Civil and Environmental Engineering, Pulau Pinang, Malaysia, 2015.

[11] KH Jyothirmayi, T Gnanananda and K Suresh. Prediction of compaction characteristics of soil using plastic limit. Int. J. Res. Eng. Tech. 2015; 4, 253-6.

[12] H Arif, MM Hasan, MR Islam and MA Alim. Prediction of compaction parameters of soil using support vector regression. Curr. Trends Civ. Struct. Eng. 2019; 4, 000580.

[13] W Firomsa and ET Quezon. Parametric modelling on the relationships between atterberg limits and compaction characteristics of fine-grained soils. Int. J. Adv. Res. Eng. Appl. Sci. 2019; 8, 1-20.

[14] A Hussain and C Atalar. Estimation of compaction characteristics of soils using atterberg limits. In: Proceedings of the $5^{\text {th }}$ International Conference on New Advances in Civil Engineering, Kyrenia, Cyprus, 2020.

[15] AA Fondjo and E Theron. Application of mathematical function to estimate the compaction characteristics of unsaturated soils. Civ. Eng. Architect. 2021; 9, 255-62. 
http://wjst.wu.ac.th

[16] ASTM. Standard test method for particle-size distriution (gradation) of soils using sieve analysis. American Society for Testing and Materials, PA, USA, 2009.

[17] ASTM. Standard test method for particle-size distribution (gradation) of fine-grained soils using the sedimentation (hydrometer) analysis. American Society for Testing and Materials, PA, USA, 2016.

[18] ASTM. Standard test method for liquid limit, plastic limit, and plasticity index of soils. American Society for Testing and Materials, PA, USA, 2005.

[19] SABS. Civil engineering test methods, determination of the maximum dry density and optimum moisture content. South Africa Bureau of Standards, Pretoria, 2016.

[20] ASTM. Standard test method for the specific gravity of soils. American Society for Testing and Materials, PA, USA, 2014.

[21] RA Johnson. Miller and Freund's Probability and Statistics for Engineers. $7^{\text {th }}$ ed. Prentice Hall, New Jersey, USA, 2005.

[22] AA Fondjo and TC Dzogbewu. Assessment of stress raiser factor using finite element solvers. Univ. J. Mech. Eng. 2012; 7, 367-79. 